\author{
Mirjana Resanović, \\ dipl. inž. \\ Dr Lazar Vorkapić, \\ dipl. inž. \\ Stanojko Stojković, \\ ppuk. dipl. inž.
}

\section{TEHNOEKONOMSKI ASPEKTI REMONTA NIKL-KADMIJUMOVIH AKUMULATORA}

\section{Uvod}

U Institutu za hemijske izvore struje - Istraživanja u prvom polugođu 1994. godine izvršen je remont niza tipova i velikog broja nikl-kadmijumovih hermetičkih sinterovanih, poluhermetičkih sinterovanih i lamelnih akumulatora. $\mathrm{Na}$ osnovu dobijenih rezultata utvrđeno je koje tipove akumulatora treba remontovati. Treba napomenuti da su remontovani akumulatori predviđeni za otpis, odnosno da su bili u vrlo lošem stanju.

Remont je izveden na dva načina:

- od više neispravnih baterija posle defektacije, selekcije i remonta celija sastavljen je manji broj baterija;

- korišćena je samo kutija baterije i izvršena izmena ćelija.

Akumulatorska baterija posle uspešnog remonta treba da funkcioniše sa najmanje $80 \%$ nazivnog kapaciteta.

\section{Rezultati remonta hermetičkih nikl-kadmijumovih akumulatorskih baterija}

Rezultati remonta hermetičkih nikl-kadmijumovih akumulatorskih baterija prikazani su u tabeli 1 .

$\mathrm{Na}$ osnovu dobijenih rezultata može se zaključiti da se samo akumulatorska baterija 7ACH-1 ne može remontovati na ovaj način, dok se kod drugih baterija koeficijent korišćenja kreće iznad 50\%. Naravno, kada se radi o akumulatorskim baterijama gde je kućište značajna stavka u ceni baterije $(7 \mathrm{ACH}-$ -1 , za laserske nišane, $P R C$, itd.), isplati se korišćenje stare kutije i ugradnja novih ćelija. U tom slučaju koeficijent iskorišćenja je $100 \%$.

\section{Rezultati remonta poluhermetičkih nikl-kadmijumovih akumulatorskih baterija sa sinterovanim elektrodama}

Izvršen je remont 4 baterije 20 VO $52 \mathrm{U}$, proizvodnje SAFT (Francuska), na bazi ćelija iz 5 baterija. Baterija 


\begin{tabular}{|c|c|c|c|c|c|c|}
\hline $\begin{array}{c}\text { Red. } \\
\text { br. }\end{array}$ & Oznaka baterije & $\begin{array}{c}\text { Napon } \\
(\mathrm{V})\end{array}$ & $\begin{array}{c}\text { Kapa- } \\
\text { citet } \\
(\mathrm{Ab})\end{array}$ & Kućište & $\begin{array}{c}\text { Prim- } \\
\text { ljeno } \\
\text { kom. }\end{array}$ & $\begin{array}{c}\text { Remonto- } \\
\text { vano } \\
\text { kom/\% }\end{array}$ \\
\hline 1 & 2 & 4 & 5 & 6 & 7 \\
\hline 1. & 10 TB 6 & 12 & 6 & Plastično & 61 & $46 / 75$ \\
\hline 2. & 10 TB/VR 7 & 12 & 7 & Plastično & 28 & $17 / 61$ \\
\hline 3. & 7 ACH-1 & 8,4 & 0,5 & Plastično & 183 & $183 / 12$ \\
\hline 4. & 7 TB-045 & 8,4 & 0,5 & Plastično & 157 & $87 / 55$ \\
\hline 5. & $612 A-1$ & 25,2 & 1,8 & Metalno & 8 & $5 / 62$ \\
\hline 6. & Za laserski nišn & 24 & 1,0 & Metalno & 12 & $11 / 92$ \\
\hline
\end{tabular}

\begin{tabular}{|c|c|c|}
\hline $\begin{array}{c}\text { Red. } \\
\text { br. }\end{array}$ & Karakteristika & Vrednost \\
\hline 1 & 2 & 3 \\
\hline 1. & Nazivni napon (V) & 1,2 \\
\hline 2. & $\begin{array}{l}\text { Krajnji napon punje- } \\
\text { nja (V) }\end{array}$ & 1,6 \\
\hline 3. & $\begin{array}{l}\text { Kapacitet pri režimu } \\
\mathrm{C}_{1} \text { (pražnjenje strujom } \\
\text { od } 52 \mathrm{~A} \text { do napona } 1 \\
\text { V) }(\mathrm{Ah})\end{array}$ & 52 \\
\hline 4. & $\begin{array}{l}\text { Krajnji napon praž- } \\
\text { njenja pri režimu } C_{1}\end{array}$ & 1,0 \\
\hline 5. & $\begin{array}{l}\text { Napon punjenja na } 20^{\circ} \\
\text { C/metoda konstantnog } \\
\text { napona (V) }\end{array}$ & 1,43 \\
\hline 6. & Oblik i dimenzije & $\begin{array}{l}\text { Prizmatic. } \\
75,6 \times 41,6 x \\
\quad \times 221\end{array}$ \\
\hline 7. & Masa (kg) & 2,1 \\
\hline 8. & Kućište & Celično \\
\hline
\end{tabular}

20 VO 52 sastoji se od 20 ćelija, čije su tehničke karakteristike prikazane $u$ tabeli 2 .

Akumulatorske ćelije bile su stare Tabela 2 između 8 i 12 godina, eksploatisane su, i za to vreme nisu održavane. Baterije 20 VO 52 U su pri prijemu bile u takvom stanju da se nisu mogle napuniti. Demontažom, selekcijom i remontom osposobljene su 4 baterije, čije su karakteristike pražnjenja prikazane na sl. 1.

Tom prilikom vršen je remont uređaja koji održava bateriju. Rezultati ispitivanja na samom uređaju prikazani su na sl. 2. i 3. Remontovane baterije nalaze se već šest meseci u eksploataciji i ne pokazuju znake slabljenja.

\section{Rezultati remonta poluhermetičkih nikl-kadmijumovih akumulatorskih baterija sa lamelnim elektrodama}

Rezultati remonta poluhermetičkih nikl-kradmijumovih akumulatorskih baterija sa lamelnim elektrodama prikazani su u tabeli 3 . 


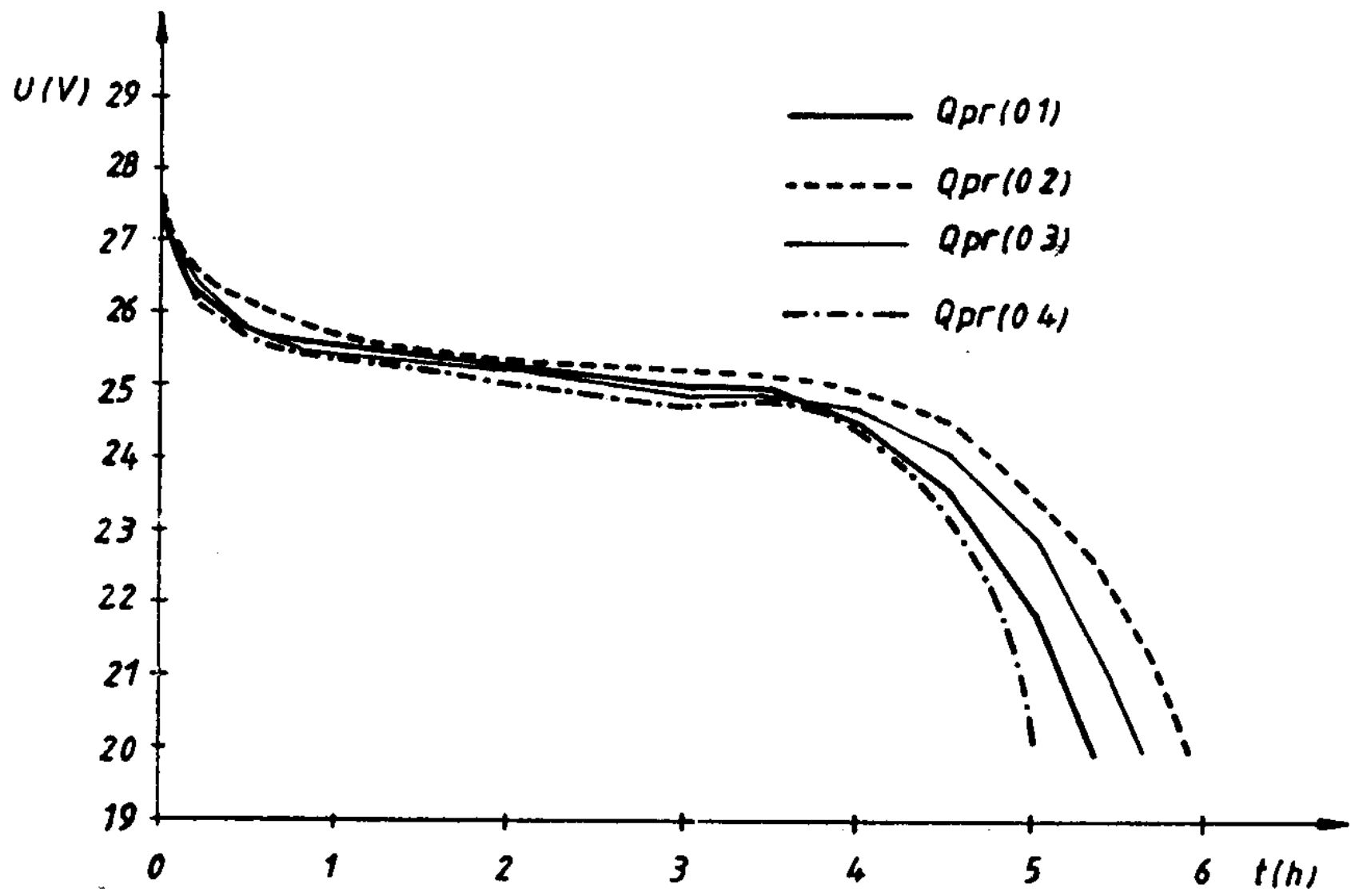

Sl. 1 - Karakteristike pražnjenja za akumulatorske baterije 20 VO $52 \mathrm{U}$ br. 01, 02, 03 i 04 pri konstantnoj struji 10,4 A u III ciklusu

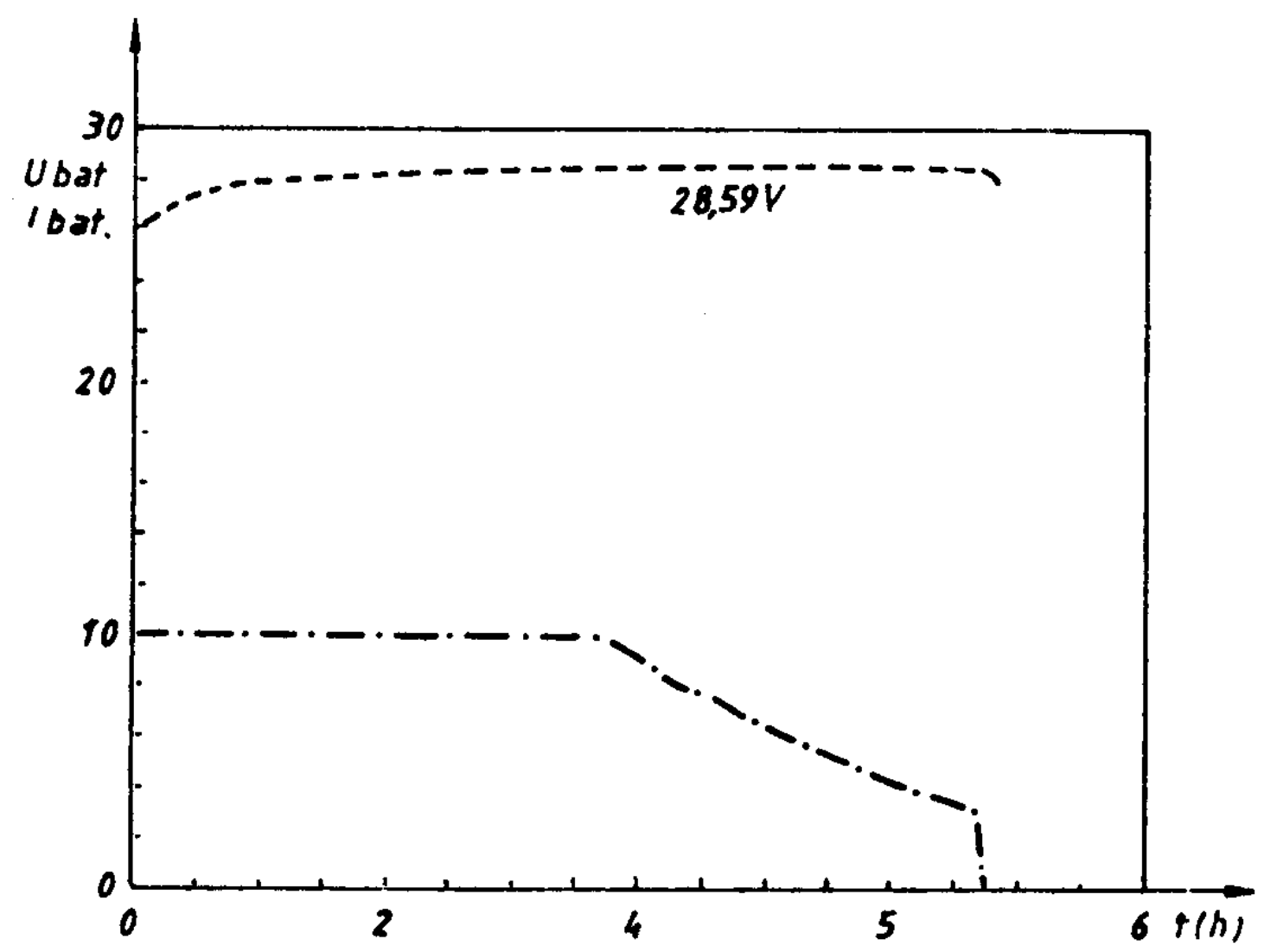

Sl. 2 - Karakteristika punjenja baterije 20 VO $52 U^{* 1}$ 


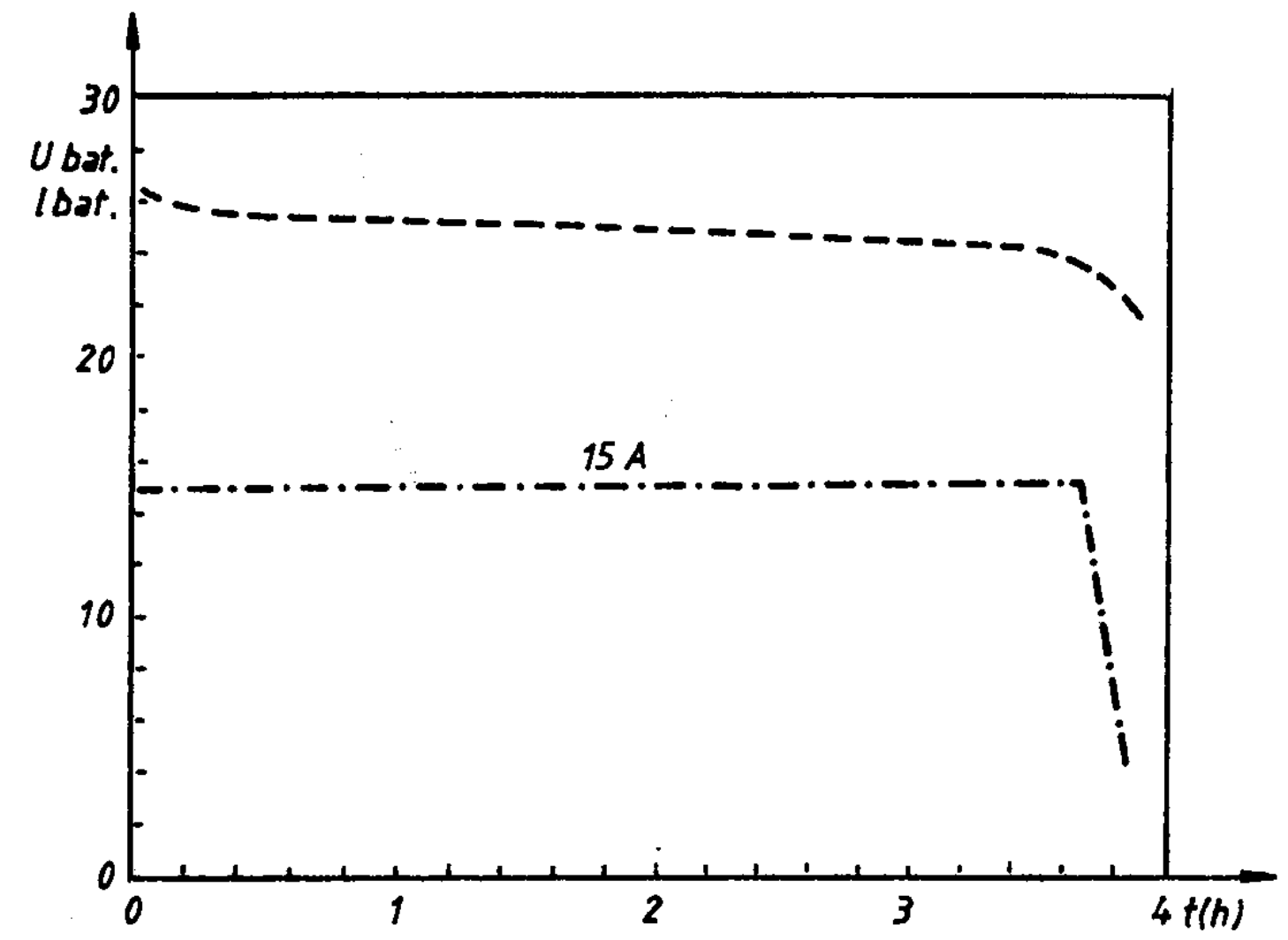

Sl. 3 - Karakteristika pražnjenja baterije 20 VO 52U*1

Tabela 3

\begin{tabular}{|c|c|c|c|c|c|c|}
\hline $\begin{array}{c}\text { Red. } \\
\text { br. }\end{array}$ & Oznaka & $\begin{array}{c}\text { Napon } \\
\text { (V) }\end{array}$ & $\begin{array}{c}\text { Kapa- } \\
\text { citet } \\
\text { (Ah) }\end{array}$ & Kućište & $\begin{array}{c}\text { Prim- } \\
\text { ljeno } \\
\text { (kom) }\end{array}$ & $\begin{array}{c}\text { Remonto- } \\
\text { vano } \\
(\mathrm{kom} / \%)\end{array}$ \\
\hline 1 & 2 & 3 & 4 & 5 & 6 & 7 \\
\hline 1. & 10 AKP 6 & 12 & 6 & Plastično & 146 & $58 / 40$ \\
\hline 2. & NKN-10 & 2,4 & 10 & Metalno & 87 & $42 / 54$ \\
\hline 3. & AK-2-I & 2,4 & 25 & Metalno & 261 & $140 / 54$ \\
\hline 4. & 5 AK-30 & 6,0 & 30 & Metalno & 104 & $82 / 79$ \\
\hline
\end{tabular}


Na osnovu rezultata remonta može se zaključiti da je koeficijent korišćenja

\begin{tabular}{|l|l|l|}
\hline $\begin{array}{c}\text { Red. } \\
\text { br. }\end{array}$ & T i p & $\begin{array}{c}\text { Relativna vred- } \\
\text { nost (\%) } \mathrm{u} \text { odno- } \\
\text { su na novu aku- } \\
\text { mulatorsku ba- } \\
\text { teriju }\end{array}$ \\
\hline 1 & 2 & 3 \\
\hline 1. & 10 TB-6/7 & 14 \\
\hline 2. & 10 VR 7 & 14 \\
\hline 3. & 7 ACH $1^{*}$ & 54 \\
\hline 4. & 7 TB-045 & 21 \\
\hline 5. & $612 \mathrm{~A}-1$ & 26 \\
\hline 6. & $\begin{array}{l}\text { Za laserski ni- } \\
\text { San }\end{array}$ \\
\hline 7. & 20 VO 52 U & 24 \\
\hline 8. & 10 AKP 6 & 15 \\
\hline 9. & NKN 10 \\
\hline 10. & AK-2-1 & 18 \\
\hline 11. & 5 AK-30 \\
\hline
\end{tabular}

* Za slučaj kada se vrši kompletna zamena ćelija nešto niži $u$ odnosu na hermetičke akumulatore, posebno kod 10 AKP 6, i to zbog toga što su korodirali polovi. Odgovarajućim održavanjem ovaj koeficijent bio bi znatno uvećan i kod 10 AKP 6.

Relativna vrednost remonta po tipovima, $u$ odnosu na vrednost novih akumulatorskih baterija, prikazana je u tabeli 4.

\section{Zaključak}

Očigledno je da se ovakva vrsta remonta izuzetno isplati, posebno ako se ima $u$ vidu da se neke od remontovanih baterija nalaze u upotrebi duže od šest meseci. U tom smislu, usvojen je tehnološki postupak remonta hermetičkih i poluhermetičkih akumulatora i osposobljena radionica za takvu vrstu posla u Institutu za hemijske izvore struje - Istraživanja. 